\title{
Analytic Hierarchy Process (AHP) for a Power Transmission Industry to Vendor Selection Decisions
}

\author{
Jitendra Kumar \\ Department of Mechanical \\ Engineering, MNNIT \\ Allahabad, India
}

\author{
Nirjhar Roy \\ Department of Mechanical \\ Engineering, MNNIT \\ Allahabad, India
}

\begin{abstract}
This work attempts to develop a rule based model, to evaluate the performance of vendors, supplying components and raw materials to a multinational organization engaged in designing, manufacturing and delivering a range of products covering various stages of electric power transmission and distribution system. The analytic hierarchy process (AHP) based model, described in this work, is utilized to study the requirements of customers to select suitable vendors validate the model for ordering required components and materials for customers.
\end{abstract}

\section{Keywords}

Supply chain, Optimization, Vendor selection, Networking, method of AHP

\section{INTRODUCTION}

Proper identification of vendors is important for increasing the efficiency of service and manufacturing organizations. For this reason any organization is required to select suitable vendors who can supply a host of materials and components to the organisation as per the need. The purchased department focuses more on "A" types of items for administrative purposes. Most of the time the purchasing department uses some tools for decision making to evaluate vendors.

It is also pertinent to note that supply chains (SC), can be viewed as a network of vendors, manufacturers, distributors, and retailers. The efficiency of the network is dictated mainly by the characteristics of vendors and also is influenced by mode of transportation, information flow, and financial infrastructure. The ability to represent a complex but realistic supply chain of any organization by using any model is often difficult if the organization supplies customized products to its customers. The preferences of vendors from customers side create further problems.. The variable market condition also requires that in any organization specific SC models must be developed and applied.

This paper considers the case of a manufacturing organisation which provides as in [15] comprehensive electrical solutions for utilities and electro-intensive industries engaged in (a) transmission, distribution and power generation, (b)railways, (c)industrial buildings and mining and metal industries. The manufacturing organisation, under consideration has multi-plants and are located in several countries. Vendors are distributed evenly in those countries and the organisation attempts to purchase raw materials and components from local suppliers.

Some of the customers of this organisation also require certain components (or raw materials) to be purchased directly from their selected vendor. Price may not be the criteria for these purchases. For these cases the manufacturer does not have the freedom to select the vendors themselves on the basis on cost or time parameters. No systematic procedure or mathematical model is applicable for such situations. A rule-based algorithm may therefore become effective.
The manufactured items are power transformers of various sizes and specifications.. It may be noted that a customer may opt for any type of transformers as per their need.

\section{LITERATURE SURVEY}

Many research methodologies of vendor analysis have been in used and published in literatures. For an extensive review of literatures please refer [7]. Also the works as in [19] and [8] are very informative and contains reviews of previous researches.

The work as in [6] is considered as the first published research work in the direction of vendor selection and is meaningful for research purposes. The terms vendor and supplier are often mean same and used interchangeably.

Traditional methods of vendors evaluation in the early $80 \mathrm{~s}$ are mainly based on buyer's experience. The qualitative methodology have utilised in [17] and [25] for performance evaluation of vendors. Qualitative methods may include tools for visualizing and analysing the decision-maker's perception of a problem situation and tools for brainstorming about possible (alternative) solutions.

In the domain of quantitative techniques, A series of research papers [3-5] had published which addressed to solve cost based optimization problem. Research paper [23] had improvised the previous paper as in [22] and developed a multi objective programming model to fix number of suppliers/vendors. Though the list of such researches is wide and the techniques range from linear programming to highly complex mathematical modelling are often found to be NP hard. Thus practical and realistic models are more preferred for vendor selection by industrial organisations. The quantitative techniques cause significant problems in considering qualitative factors. The models which can combine subjective and quantitative criteria are more useful for practical application. Hybrid system had implemented to solve vendor selection method [20]. It had also attempted to quantify the attributes like quality, cost and delivery parameters so as to make the selection of vendors more justified as in [19].

For dealing with multi-level criteria for vendor selection, analytic hierarchy process (AHP) had widely been in use for solving such problems. A web-based AHP system [1] had been developed and initially utilised in [14] to evaluate the suppliers of casting with respect to 18 different criteria.. A five-step AHP - based model [11] had proposed to aid decision makers in rating and selecting suppliers with respect to nine evaluating criteria. An AHP methodology [18] based on a combined AHP and a genetic algorithm (GA) also developed. Another integrated model using GA as in [21]. However GA in vendor selection is not much utilised.

Data envelopment approaches (DEA) is also another technique which had been applied to fix alternative vendors on the basis of their performances. This approach is regarded as simple and can also accommodate subjective information like experience, insight 
and intuition of the selector in logical manner. It had reported that a majority of research work on vendor selection area is based on DEA [7]. The work as in [15], [16] and [24] are frequently cited as DEA approaches.

Artificial neural network (ANN) based algorithms had developed in [9], [13], and [12]. ANN based algorithms are claimed to be helpful for practical industrial applications especially for dynamic situations.

In many realistic applications, organizations have utilized their own methods as illustrated in [2] and [10]. The experience of the management staff is often seen to generate acceptable results in decision making process by using rules of thumb and are not reported in literature. Dependency on use of theoretical models are avoided mostly by such industrial organizations.

In the following, section 3 provides the methodology utilized in this paper. Section 4 gives the AHP results and further discussion. Finally, our conclusions are presented in section 6 .

\section{MODEL AND METHODOLOGY}

The following AHP model is to select the best vendor and know the performance (score) of each vendor.

\subsection{AHP vendor selection model}

A method of analytic hierarchy process (AHP) for the fixation of vendors is described hereunder.

Step 1: Structure of the decision problem in a hierarchy of goal (best vendor), criteria and alternatives (vendors). The criteria here are taken as an illustrative example as quality of the product expressed in percentage of rejected parts, delay time, unit cost of the input and quality of service of the vendors. The relative importance given for these criteria may be considered as w1, w2, w3 and w4. These values of relative importance " $\mathrm{w}_{\mathrm{i}} \mathrm{s}$ " are not known by the manufacturers and the decision criteria of the customers may react in different ways. Fig.1. shows the diagrammatic representation of the AHP model.

Step 2: Compare the alternatives based on the criteria which is adapted from a common scale [14].

Step 3: Synthesize the comparisons to get the priorities of the alternatives with respect to each criterion and the weights of each criterion with respect to the goal. Local priorities are then multiplied by the weight of the respective criterion and the results are summed up to produce the overall priority of each alternative (vendor).

\subsection{Algorithm}

1. Scaling the criteria (which criteria is important?) according to goal (select the best vendor wrt to important criteria).

2. Pair wise comparison each criteria to obtain the average value of each criteria.

3. Pair wise comparison of vendors with respect to each criteria to obtain the average value of each vendor with each criteria.

4. Arranged the values for final matrix by multiplication of average value of each criteria and average value of each vendor with each criteria.

5. Summation of all value in each row to obtain the value for vendors.

6. Arranged final matrix in descending order of value for vendor.

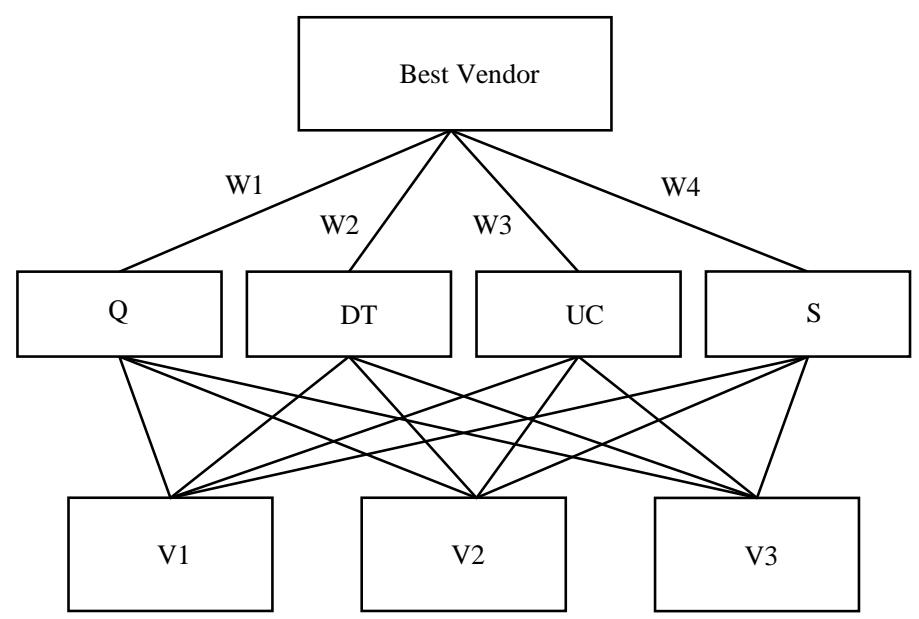

Fig.1. A AHP model for vendor selection of a transformer industry

\section{NUMERICAL ILLUSTRATION}

\subsection{Data}

The data is derived from a large, multinational, transformer company, which is a global leader in design, production, and marketing of power and distribution transformers systems. Table-1 shows the data of of the quality (Q), delay times (DT), unit cost (UC) and services(S) of seven vendors.

\begin{tabular}{|l|c|c|c|c|}
\hline V & $\begin{array}{l}\text { Q (\% } \\
\text { R.P.) }\end{array}$ & DT (Days) & $\begin{array}{l}\text { UC } \\
\text { (Rs.) }\end{array}$ & S \\
\hline V1 & 1 & 5 & $1.85 \mathrm{LAC} / \mathrm{T}$ & $\mathrm{AV}$ \\
\hline V2 & 1 & 4 & $2.68 \mathrm{LAC} / \mathrm{T}$ & $\mathrm{G}$ \\
\hline V3 & 2 & 10 & $2.31 \mathrm{LAC} / \mathrm{T}$ & $\mathrm{O}$ \\
\hline V4 & 5 & 12 & $2.55 \mathrm{LAC} / \mathrm{T}$ & $\mathrm{G}$ \\
\hline V5 & 3 & 11 & $2.01 \mathrm{LAC} / \mathrm{T}$ & $\mathrm{VG}$ \\
\hline V6 & 2 & 18 & $2.71 \mathrm{LAC} / \mathrm{T}$ & $\mathrm{O}$ \\
\hline V7 & 0 & 15 & $2.85 \mathrm{LAC} / \mathrm{T}$ & $\mathrm{AV}$ \\
\hline
\end{tabular}

Table 1. Vendor data

O-Outstanding, VG-Very good, G-Good, AV-Average, PPoor

\subsection{Implementation and calculation}

The above steps can be illustrated with the data shown in Table-1.

Scaling the criteria with respect to important criteria (i.e. quality).

Quality is somewhat more important than delay time - 3

Quality is much more important than unit cost -5

Quality is very much more important than service -7

Delay time is somewhat more important than unit cost -3

Delay time is much more important than service -5

Unit cost is somewhat more important than service -3

Consider a data sheet of seven vendors of a component. Table- 1 shows the quality, delay times unit cost and services of vendors. The method as shown on the left hand side of the page is used. The tables 2 and 3 are showing the pair wise comparison of criteria and weight on objective with respect to goal (preference on quality).The table 4 and 5 are showing 
pair wise comparison of vendors with respect to quality and its weight from vendor data.

In this industry for quality maximum rejection parts is $8 \%$ and total scale is divided from $1 \%$ to $8 \%$ (i.e. for difference of 0\%-1, 1\%-2, 2\%-3, 3\%-4, 4\%-5, 5\%-6, 6\%-7, 7\%-8, 8\%-9). For delay times maximum days is 15 and these days are divided into scale of 1 to 9 (i.e. for difference of $0=1,1-2=2$, $3=3,4-5=4,6=5,7-8=6,9=7,10-11=8,12-15=9$ ).

For unit cost the total difference of cost is $1.00 \mathrm{Lac} / \mathrm{T}$ (i.e. $2.85-1.85=1.00)$ and difference of each component cost has been taken and scale is used for these differences between 1-9 (i.e. for difference of $0=1$, up to. $125=2, .126-.250=3, .251$ $.375=4, .376-.500=5, .501-625=6, .626-. .750=7, .751-.875=8$, $.876-1.00=9)$.

For service scale is divided between $\mathrm{P}$ to $\mathrm{O}$ (Poor to Outstanding i.e. $\mathrm{P}=2, \mathrm{~A}=3, \mathrm{G}=5, \mathrm{VG}=7, \mathrm{O}=9$ ) by 1 to 9 (i.e. for difference of $1-2=2,3=3,4-5=5,6-7=7,8-9=9$ ).

All value is obtained by pair wise comparison of vendors with respect to delay times, unit cost and service and arranged in the next tables ( table 6 to table 11). Table 12 and 13 (i.e. $.559 x .19+.262 \times .30+.122 \times .41+.057 x .03=.236)$ are final matrix of vendors which are showing the final ranking of vendors by descending order of weights.

\section{Table 2. Performance on criteria}

\begin{tabular}{|c|c|c|c|c|}
\hline CR & Q & DT & UC & S \\
\hline Q & 1 & 3 & 5 & 7 \\
\hline DT & $1 / 3$ & 1 & 3 & 5 \\
\hline UC & $1 / 5$ & $1 / 3$ & 1 & 3 \\
\hline S & $1 / 7$ & $1 / 5$ & $1 / 3$ & 1 \\
\hline
\end{tabular}

Table 3. Weight on objectives

\begin{tabular}{|c|c|c|l|l|l|}
\hline CR & Q & DT & UC & S & AV \\
\hline Q & .598 & .662 & .536 & .438 & .559 \\
\hline DT & .197 & .221 & .322 & .313 & .262 \\
\hline UC & .119 & .073 & .107 & .188 & .122 \\
\hline S & .085 & .044 & .035 & .063 & .057 \\
\hline
\end{tabular}

Table 4. Relative matrix of vendors with respect to quality

\begin{tabular}{|c|c|c|c|c|c|c|c|}
\hline & V1 & V2 & V3 & V4 & V5 & V6 & V7 \\
\hline V1 & 1 & 1 & 2 & 5 & 3 & 2 & $1 / 2$ \\
\hline V2 & 1 & 1 & 2 & 5 & 3 & 2 & $1 / 2$ \\
\hline V3 & $1 / 2$ & $1 / 2$ & 1 & 4 & 2 & 1 & $1 / 3$ \\
\hline V4 & $1 / 5$ & $1 / 5$ & $1 / 4$ & 1 & $1 / 3$ & $1 / 4$ & $1 / 6$ \\
\hline V5 & $1 / 3$ & $1 / 3$ & $1 / 2$ & 3 & 1 & $1 / 2$ & $1 / 4$ \\
\hline V6 & $1 / 2$ & $1 / 2$ & 1 & 4 & 2 & 1 & $1 / 3$ \\
\hline V7 & 2 & 2 & 3 & 6 & 4 & 3 & 1 \\
\hline
\end{tabular}

Table 5. Weight on quality

\begin{tabular}{|l|l|l|l|l|l|l|l|l|}
\hline & V1 & V2 & V3 & V4 & V5 & V6 & V7 & AV \\
\hline V1 & .18 & .18 & .21 & .18 & .20 & .21 & .16 & .19 \\
\hline V2 & .18 & .18 & .21 & .18 & .20 & .21 & .16 & .19 \\
\hline V3 & .09 & .09 & .10 & .14 & .13 & .10 & .11 & .11 \\
\hline V4 & .04 & .04 & .03 & .04 & .02 & .03 & .05 & .03 \\
\hline V5 & .06 & .06 & .05 & .11 & .07 & .05 & .08 & .07 \\
\hline V6 & .09 & .09 & .10 & .14 & .13 & .10 & .11 & .11 \\
\hline V7 & .36 & .36 & .31 & .21 & .26 & .31 & .32 & .30 \\
\hline & & & & & & & & $\sum=1$ \\
\hline
\end{tabular}

Table 6. Relative matrix of vendors with respect to delay time

\begin{tabular}{|l|l|l|l|l|l|l|l|}
\hline & V1 & V2 & V3 & V4 & V5 & V6 & V7 \\
\hline V1 & 1 & $1 / 2$ & 4 & 6 & 5 & 9 & 8 \\
\hline V2 & 2 & 1 & 5 & 6 & 6 & 9 & 8 \\
\hline V3 & $1 / 4$ & $1 / 5$ & 1 & 2 & 2 & 6 & 4 \\
\hline V4 & $1 / 6$ & $1 / 6$ & $1 / 2$ & 1 & $1 / 2$ & 5 & 3 \\
\hline V5 & $1 / 5$ & $1 / 5$ & $1 / 2$ & 2 & 1 & 6 & 4 \\
\hline V6 & $1 / 9$ & $1 / 9$ & $1 / 6$ & $1 / 5$ & $1 / 6$ & 1 & $1 / 3$ \\
\hline V7 & $1 / 8$ & $1 / 8$ & $1 / 4$ & $1 / 3$ & $1 / 4$ & 3 & 1 \\
\hline
\end{tabular}

Table 7. Weight on delay time

\begin{tabular}{|l|l|l|l|l|l|l|l|l|}
\hline & V1 & V2 & V3 & V4 & V5 & V6 & V7 & AV \\
\hline V1 & .26 & .29 & .35 & .34 & .33 & .23 & .28 & .30 \\
\hline V2 & .52 & .58 & .43 & .34 & .40 & .23 & .28 & .40 \\
\hline V3 & .07 & .12 & .09 & .11 & .13 & .15 & .14 & .10 \\
\hline V4 & .04 & .10 & .04 & .06 & .03 & .13 & .11 & .06 \\
\hline V5 & .05 & .10 & .04 & .11 & .07 & .15 & .14 & .06 \\
\hline V6 & .03 & .07 & .02 & .01 & .01 & .03 & .01 & .03 \\
\hline V7 & .03 & .07 & .02 & .02 & .06 & .08 & .04 & .05 \\
\hline & & & & & &. & & $\sum=1$ \\
\hline
\end{tabular}

Table 8. Relative matrix of vendors with respect to unit cost

\begin{tabular}{|l|l|l|l|l|l|l|l|}
\hline & V1 & V2 & V3 & V4 & V5 & V6 & V7 \\
\hline V1 & 1 & 9 & 5 & 7 & 3 & 9 & 9 \\
\hline V2 & $1 / 9$ & 1 & $1 / 4$ & $1 / 3$ & $1 / 7$ & 2 & 3 \\
\hline V3 & $1 / 5$ & 4 & 1 & 3 & $1 / 4$ & 5 & 6 \\
\hline V4 & $1 / 7$ & 3 & $1 / 3$ & 1 & $1 / 6$ & 3 & 4 \\
\hline V5 & $1 / 3$ & 7 & 4 & 6 & 1 & 7 & 8 \\
\hline V6 & $1 / 9$ & $1 / 2$ & $1 / 5$ & $1 / 3$ & $1 / 7$ & 1 & 3 \\
\hline V7 & $1 / 9$ & $1 / 3$ & $1 / 6$ & $1 / 4$ & $1 / 8$ & $1 / 3$ & 1 \\
\hline
\end{tabular}


Table 9. Weight on unit cost

\begin{tabular}{|l|l|l|l|l|l|l|l|l|}
\hline & V1 & V2 & V3 & V4 & V5 & V6 & V7 & AV \\
\hline V1 & .50 & .36 & .46 & .40 & .62 & .33 & .26 & .41 \\
\hline V2 & .06 & .04 & .02 & .02 & .03 & .07 & .08 & .05 \\
\hline V3 & .10 & .16 & .09 & .17 & .05 & .18 & .17 & .14 \\
\hline V4 & .07 & .12 & .03 & .06 & .03 & .11 & .11 & .08 \\
\hline V5 & .17 & .28 & .36 & .33 & .20 & .26 & .23 & .26 \\
\hline V6 & .06 & .02 & .02 & .02 & .03 & .04 & .08 & .04 \\
\hline V7 & .06 & .01 & .02 & .01 & .03 & .01 & .03 & .02 \\
\hline & & & & & &. & & $\begin{array}{l}\sum= \\
1\end{array}$ \\
& & & & & & & & \\
\hline
\end{tabular}

Table 10. Relative matrix of vendors with respect to service

\begin{tabular}{|l|l|l|l|l|l|l|l|}
\hline & V1 & V2 & V3 & V4 & V5 & V6 & V7 \\
\hline V1 & 1 & $1 / 2$ & $1 / 7$ & $1 / 2$ & $1 / 5$ & $1 / 7$ & 1 \\
\hline V2 & 2 & 1 & $1 / 5$ & 1 & $1 / 2$ & $1 / 5$ & 2 \\
\hline V3 & 7 & 5 & 1 & 5 & 2 & 1 & 7 \\
\hline V4 & 2 & 1 & $1 / 5$ & 1 & $1 / 2$ & $1 / 5$ & 2 \\
\hline V5 & 5 & 2 & $1 / 2$ & 2 & 1 & $1 / 2$ & 5 \\
\hline V6 & 7 & 5 & 1 & 5 & 2 & 1 & 7 \\
\hline V7 & 1 & $1 / 2$ & $1 / 7$ & $1 / 2$ & $1 / 5$ & $1 / 7$ & 1 \\
\hline
\end{tabular}

Table 11. Weight on service

\begin{tabular}{|l|l|l|l|l|l|l|l|l|}
\hline & V1 & V2 & V3 & V4 & V5 & V6 & V7 & AV \\
\hline V1 & .04 & .03 & .04 & .03 & .03 & .04 & .04 & .03 \\
\hline V2 & .08 & .07 & .06 & .07 & .08 & .06 & .08 & .07 \\
\hline V3 & .28 & .33 & .31 & .33 & .31 & .31 & .28 & .32 \\
\hline V4 & .08 & .07 & .06 & .07 & .08 & .06 & .08 & .07 \\
\hline V5 & .20 & .03 & .15 & .03 & .16 & .15 & .20 & .13 \\
\hline V6 & .28 & .33 & .31 & .33 & .31 & .31 & .28 & .33 \\
\hline V7 & .04 & .03 & .04 & .03 & .03 & .04 & .04 & .05 \\
\hline & & & & & &. & & $\sum=1$ \\
\hline
\end{tabular}

Table 12. Final Matrix

\begin{tabular}{|l|l|l|l|l|l|}
\hline V & Q & DT & UC & S & $\begin{array}{l}\text { Total } \\
\text { score }\end{array}$ \\
& $(.559)$ & $(.262)$ & $(.122)$ & $(.057)$ & \\
\hline V1 & .19 & .30 & .41 & .03 & .236 \\
\hline V2 & .19 & .40 & .05 & .07 & .220 \\
\hline V3 & .11 & .10 & .14 & .32 & .123 \\
\hline V4 & .03 & .06 & .08 & .07 & .048 \\
\hline V5 & .07 & .06 & .26 & .13 & .096 \\
\hline V6 & .11 & .03 & .04 & .33 & .092 \\
\hline V7 & .30 & .05 & .02 & .05 & .187 \\
\hline
\end{tabular}

Table 13. Arranged final matrix

\begin{tabular}{|l|l|l|l|l|l|}
\hline $\mathrm{V}$ & $\mathrm{Q}$ & $\mathrm{DT}$ & $\mathrm{UC}$ & $\mathrm{S}$ & $\begin{array}{l}\text { Total } \\
\text { score }\end{array}$ \\
\hline $\mathrm{V} 1$ & .19 & .30 & .41 & .03 & .236 \\
\hline $\mathrm{V} 2$ & .19 & .40 & .05 & .07 & .220 \\
\hline $\mathrm{V} 7$ & .30 & .05 & .02 & .05 & .187 \\
\hline V3 & .11 & .10 & .14 & .32 & .123 \\
\hline V5 & .07 & .06 & .26 & .13 & .096 \\
\hline V6 & .11 & .03 & .04 & .33 & .092 \\
\hline V4 & .03 & .06 & .08 & .07 & .048 \\
\hline
\end{tabular}

\subsection{Validation of proposed model \&Vendor selection}

In our example we have taken data of seven vendors of a component with some important criteria. Table 12 and 13 are showing the final ranking of vendors by descending order of weights. So finally we can say that vendor 1 (V1) is the best vendor because it has maximum weight (.236) from all other seven vendors of supplying this component. For validation of this method through vendor data (table 1) that vendor 1 has less rejection parts, less delay time, less unit cost and average service against other vendors, so vendor 1 is the best. In this paper quality has much effect on total score of vendor because quality is main objective for selection of vendor.

\section{DISCUSSION}

The goal of using AHP is to determine relative ranking of vendors. To use it, decision makers must compare all pairs of criteria and suppliers using a ratio scale. The accuracy of the comparisons is dependent upon the information available to the decision makers and the depth of the decision maker's understanding of the problem being considered. AHP method for vendor selection is very easy to understanding and accurate but it is time taken process because it involves comparison of all criteria to one another.

\section{CONCLUSIONS}

This paper considers selection of vendors for a manufacturing organisation supplying customised power transformers to its customers. The organisation gets the input materials from its vendors but for certain items, the customers identify the vendors themselves from whom the material is to be purchased. For these type of manufacturing organisations where the customers identify certain vendors themselves, the system of vendors selection cannot be done by using any conventional model. A method is therefore needed. In this paper an AHP is developed and used to justify the selection of vendors for all the important items and the management found the model useable.

\section{REFERENCES}

[1] Akarte, M. M., Surendra, N.V., Ravi, B., and Rangaraj N. 2001. Web based casting supplier evaluation using analytical hierarchy process. Journal of the Operational Research Society, Vol. 52, no. 5, pp. 511-522. 
[2] Boer, L. De, Van der Wegen, L., and Telgen, J. 1998. Outranking methods in support of supplier selection. European Journal of Purchasing and Supply Management, vol. 4, no. 2/3, pp.109-118.

[3] Degraeve, Z. and Roodhooft, F. 1998. Determining sourcing strategies: a decision model based on activity and cost driver information. Journal of the Operational Research Society, vol. 49, no. 8, pp. 81-789.

[4] Degraeve, Z. and Roodhooft, F. 1999. Improving the efficiency of the purchasing process using total cost of ownership information: the case of heating electrodes at Cockerill Sambre S. A. European Journal of Operational Research, vol.112, no. 1, pp. 42-53.

[5] Degraeve, Z. and Roodhooft, F. 2000. A mathematical programming approach for procurement using activity based costing. Journal of Business Finance and Accounting, vol. 27, no. (1-2), pp. 69-98.

[6] Dickson, G. W. 1966. A analysis of vendor selection systems and decisions. J. Purch, vol. 2, pp. 5-17.

[7] Ho, W., Xu, X., and Dey, P. K. 2010. Multi - criteria decision making approaches for supplier evaluation and selection: A literature review. European Journal of Operational Research, vol. 202, pp.16-24.

[8] Huang, S. H. and Keskar, H. 2007. Comprehensive and configurable metrics for supplier selection. International Journal of Production Economics, vol. 105, no. 2, pp. 510-523.

[9] Larson, G. B. 1995. An ANN pruning algorithm based approach to vendor selection. Journal of Systems Management (USA), vol. 46, no. 5, pp. 56-60.

[10] Mohammad Ebrahim, R., Razmi, J., and Haleh, H. 2009. Scatter search algorithm for supplier selection and order lot sizing under multiple price discount environment. Advances in Engineering Software, vol. 40, pp. 766-776.

[11] Muralidharan, C., Anantharaman, N., and Deshmukh, S. G. 2002. A multi-criteria group- decision making model for supplier rating. Journal of Supply Chain Management, vol. 38, no. 4, pp. 22-33.

[12] Ozdemir, D., and Temur, G. T. 2009. DEA ANN approach in supplier evaluation system. World Academy of Science, Engineering and Technology, 54.

[13] Quin, L. 2009. An ANN pruning algorithm based approach to vendor selection. Kybernetes, vol. 38, 3-4, pp. 314-320.
[14] Saaty, T. L. 1980. The analytic hierarchy process. New York: McGraw-Hill.

[15] Seydel, J. 2006. Data environment analysis for decision support. Industrial Management and data systems, vol. 106, no. 1, pp. 81-95.

[16] Talluri, S. and Narasimhan, R. 2004. A methodology for strategic sourcing. European Journal of Operation Research, vol. 154 , no. 1, pp. 236-250,

[17] Timmerman, E. 1986. An approach to vendor performance evaluation. Journal of Purchasing and Supply Management, vol. 1, pp. 27-32.

[18] Venkata Rao, R. 2007. Supplier selection in a supply chain using analytic hierarchy process and genetic algorithm methods. International Journal of Services and Operations Management, vol. 3, no. 3, pp. 355-369.

[19] Verma, R. and Pullman, M. E. 1998. An analysis of supplier selection process. Omega, Int. J. Mgmt. Sci. vol. 26 , no. 6, pp. 739-750.

[20] Wang, G., Huang, S. H., and Dismukes, J. P. 2004. Product-driven supply chain selection using integrated multi-criteria decision-making methodology. International Journal of production Economics, vol. 91, no. 1 , pp. 1-15.

[21] Wang, H. S., and Che, Z. H. 2007. An integrated model for supplier selection decisions in configuration changes. Expert Systems with Applications, vol. 32, pp. 1132 1140.

[22] Weber, C. A., Current, J. R., and Desai, A. 1998. Noncooperative negoation strategies for vendor selection. European Journal of Operational Research, vol. 108, pp. 208-223.

[23] Weber, C. A., Current, J. R., and Desai, A. 2000. An optimization approach to determining the number of vendors to employ. Supply Chain Management: An International Journal, vol. 5, no. 2, pp. 90-98.

[24] Wu, T., Shunk, D. Blackhurst, J. and Appalla, R. 2007. AIDEA: A methodology for supplier evaluation and selection in a supplier - based manufacturing environment. International Journal of Manufacturing Technology and Management, vol. 11, no. 2, pp. 174192

[25] Zenz, G. 1981. Purchasing and the Management of Materials. Wiley, New York. 